\begin{tabular}{c}
\hline \hline Juntendo \\
Research Profiles \\
\hline \hline Juntendo Medical Journal \\
2015. 61 (5), 532-533
\end{tabular}

\title{
Department of Plastic and Reconstructive Surgery
}

\section{Chief: Hiroshi Mizuno}

1. Tissue engineering and cell-based therapy with adipose-derived stem cells

Principle Investigator:

Hiroshi Mizuno (Professor and Chief)

Morikuni Tobita (Assistant Professor)

Since we first discovered mesenchymal stem cells within adipose tissue, termed adipose-derived stem cells (ASCs) (Zuk et al:: Tissue Eng, 2001), our research team has conducted various kinds of research using ASCs for mesenchymal tissue engineering, including fat, bone, cartilage, muscle, nerve, and vascular system, and for cell-based therapeutic approaches toward skin wound healing and tendon healing. In particular, in recent years, the versatility of using ASCs with appropriate growth factors including basic fibroblast growth factor (bFGF) and platelet-rich plasma (PRP) has been investigated for vessel maturation and cranial bone engineering, respectively (Figure-1).

\section{Peripheral nerve regeneration \\ Principle Investigator:}

Ayato Hayashi (Senior Associate Professor)

Nerve reconstruction is an important field in microsurgery, and facial reanimation is the one of our major interests clinically. To advance our strategy in nerve reconstruction, we are conducting basic research regarding end-to-side neurorrhaphy, effective usage of nerve allograft and valid methods to accelerate axonal regeneration such as brief electrical stimulation. We possess several transgenic mice strains that express fluorescent proteins in axons or Schwann cells, and developed a suitable animal model to each task. Using those mice, we could achieve unique and sophisticated evaluations for axonal regeneration and Schwann cell migration. Adding morphological and molecular aspects in our experiment, we attempted to clarify each task that could be easily applicable to a clinical setting in detail (Figure-2).

\section{Establishment of new-generation simple and effective vascular and tissue regenerative cell therapy for non-healing wounds}

Principle Investigator:

Rica Tanaka (Associate Professor)

The quality and quantity of endothelial progenitor cells (EPC), that is, CD34 + cells, are known to be impaired in diabetic patients, thereby worsening tissue repair in autologous EPC therapy. We have recently disclosed a newly developed serum-free ex vivo expansion system called Quantity and Quality Control Culture System (HyQQc) to potentiate the vasculogenic property of diabetic EPCs for enhanced vasculogenesis and tissue repair from a small amount of peripheral blood. We have demonstrated that the QQc system of autologous peripheral blood mononuclear cells (MNC) significantly enhances vasculogenesis and wound healing compared with previously reported vascular cell therapy. With our technology, we can perform vascular and tissue regenerative cell therapy with just $200 \mathrm{ml}$ of blood. We are now starting a clinical trial with this new technology for non-healing wounds. Our technology will establish an outpatient-based, simple and effective new-generation cell therapy for the first time (Figure-3).

\section{References}

1) Tobita M, Uysal AC, Xin G, Hyakusoku H, Mizuno H:

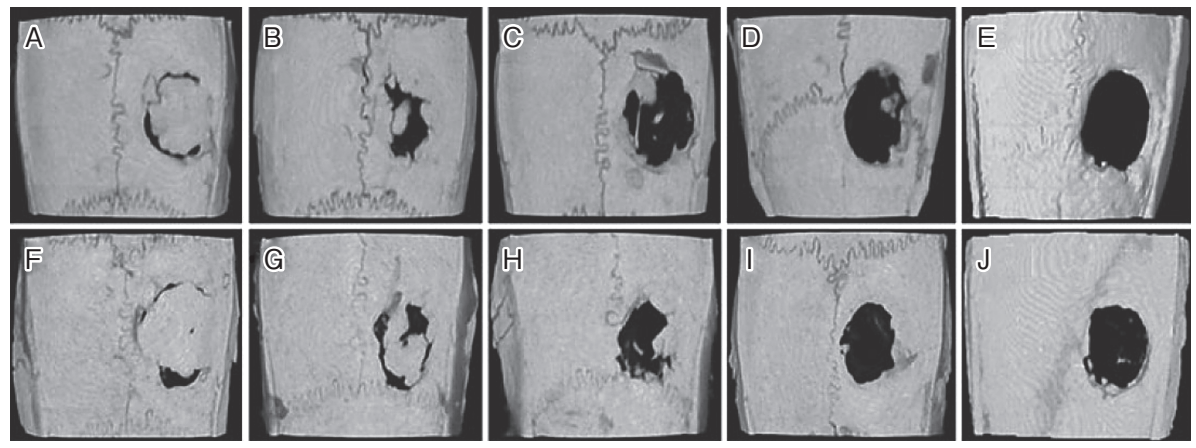

Figure-1 Micro-CT images of bone defects in each group at 4 weeks (A-E) and 8 weeks $(\mathrm{F}-\mathrm{J})$ after transplantation (A and F: ASCs/PRP group, B and G: ASCs/type I collagen gel group, C and H: PRP group, D and I: type I collagen gel group, $\mathrm{E}$ and J: PBS group) 

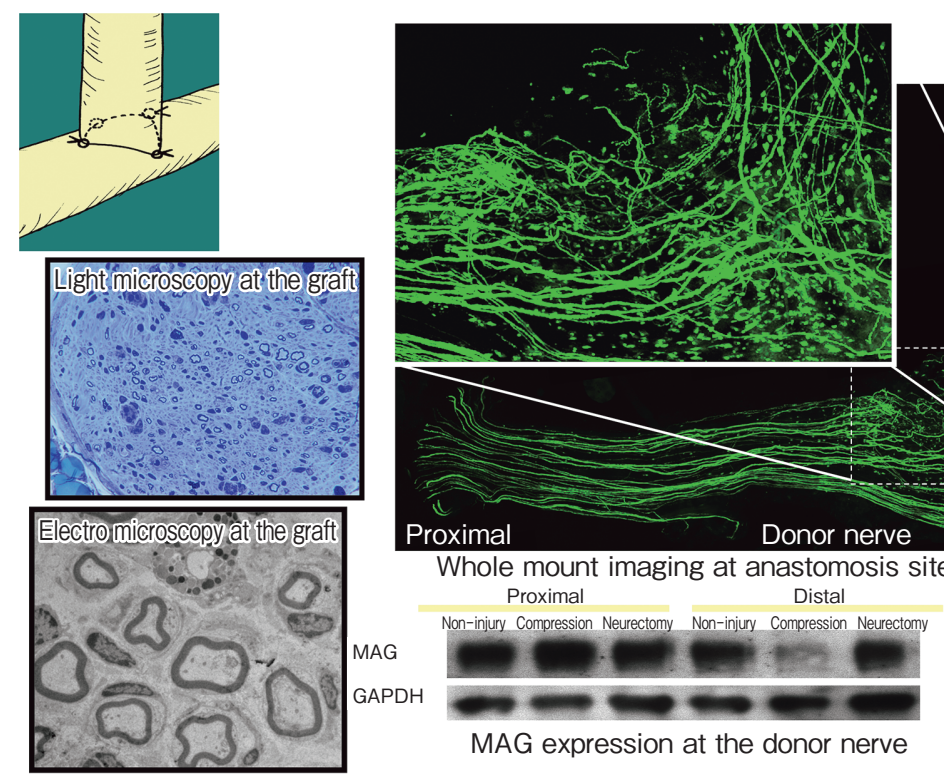

MAG expression at the donor nerve
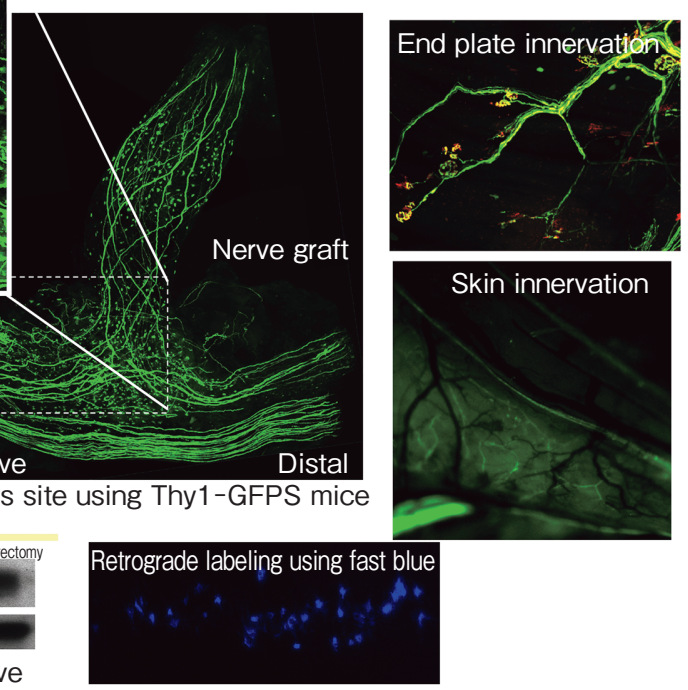

Figure-2 Multiple evaluations to clarify how the axons regenerate through the end-to-side neurorrhaphy With these results, we concluded that some types of injury is required to induce motor nerve regeneration through end-to- side neurorrhaphy.

(Cited from Hayashi et al: Experimental Neurol, 2008)

【Purpose】

To test the efficacy of our novel ex vivo culturing system named Quality and Quantity Culture (QQC) using peripheral blood MNCs for non-healing extremity wounds.
[Novelty of our technique)

- Usage of only $200 \mathrm{~m} /$ of blood

- Out-patient based therapy

- Enhances number and vasculogenic function of vascular stem cells

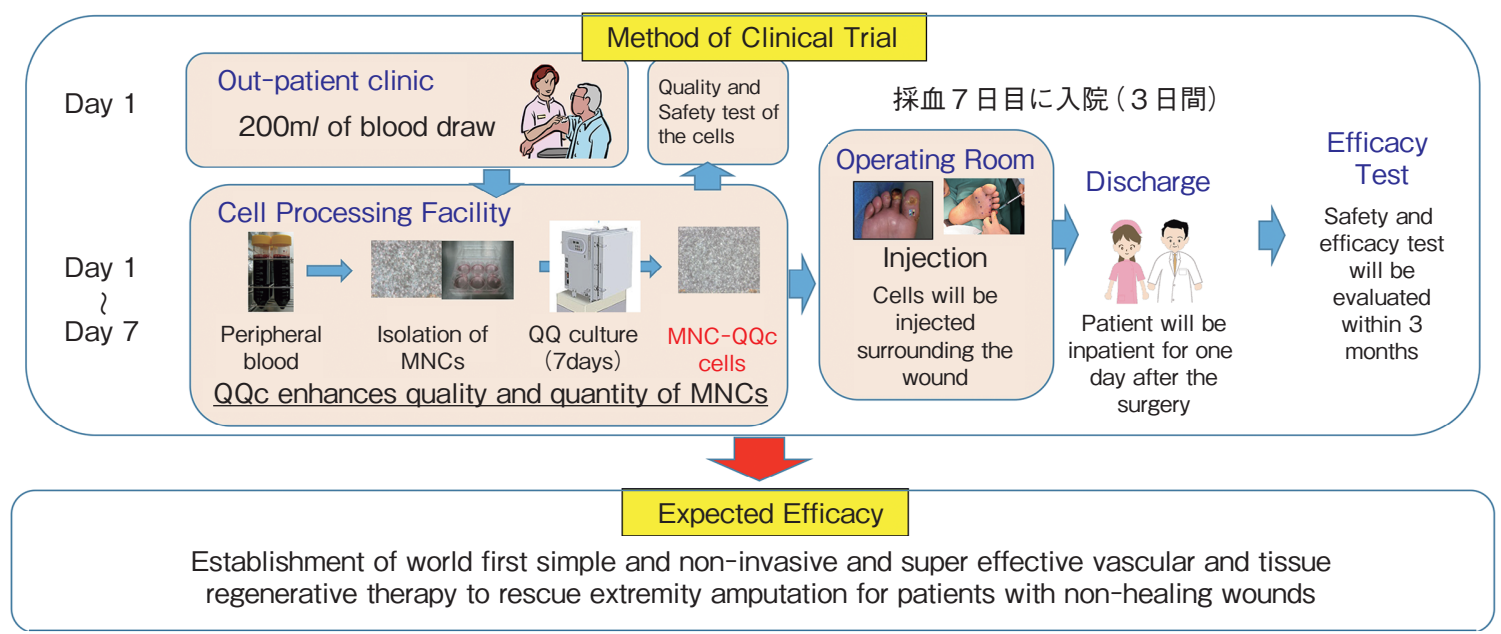

Figure-3 Clinical Trial : Ex vivo cultured peripheral blood mononuclear cell therapy for non-healing extremity wounds

Periodontal tissue regeneration by a combination of adipose-derived stem cells and platelet-rich plasma in canine model. Cytotherapy, 2013; 15: 1517-1526.

2) Mizuno H, Tobita M, Uysal AC: Adipose-derived stem cells as a novel tool for future regenerative medicine. Stem Cells, 2012; 30: 804-810.

3) Hayashi A, Nishida $M$, Seno $H$, Inoue $M$, Iwata $H$, Shirasawa T, Arai H, Kayamori R, Komuro Y, Yanai A: Hemihypoglossal nerve transfer for acute facial paralysis. J Neurosurg, 2013; 118: 160-166.

4) Hayashi A, Pannucci C, Moradzadeh A, Kawamura DH,
Magill CK, Hunter DA, Tong AY, Parsadanian A, Mackinnon SE, Myckatyn TM: Axotomy or compression are required for axonal sprouting following end-to-side neurorrhaphy. Exp Neurol, 2008; 211: 539-550.

5) Tanaka R, Vaynrub M, Masuda H, Ito R, Kobori M, Miyasaka M, Mizuno H, Warren SM, Asahara T: Quality-control culture system restores diabetic endothelial progenitor cell vasculogenesis and accelerates wound closure. Diabetes, 2013; 62: 3207-3217. 